University of South Carolina

Scholar Commons

4-2005

\title{
Correlates of Physical Activity in Persons with Arthritis: Review and Recommendations
}

\author{
Sarah Wilcox \\ University of South Carolina - Columbia, swilcox@sc.edu \\ Cheryl Der Ananian \\ Patricia A. Sharpe \\ University of South Carolina - Columbia, SHARPEP@mailbox.sc.edu \\ Jennifer Robbins \\ Theresa Brady
}

Follow this and additional works at: https://scholarcommons.sc.edu/

sph_physical_activity_public_health_facpub

Part of the Public Health Commons

\section{Publication Info}

Published in Journal of Physical Activity and Health, Volume 2, Issue 2, 2005, pages 230-252.

Wilcox, S., Der Ananian, C., Sharpe, P. A., Robbins, J., \& Brady, T. (2005). Correlates of physical activity in persons with arthritis: Review and recommendations. Journal of Physical Activity and Health, 2(2), 230-252.

(c) Journal of Physical Activity and Health, 2005, Human Kinetics

This Article is brought to you by the Physical Activity and Public Health at Scholar Commons. It has been accepted for inclusion in Faculty Publications by an authorized administrator of Scholar Commons. For more information, please contact digres@mailbox.sc.edu. 


\title{
Correlates of Physical Activity in Persons with Arthritis: Review and Recommendations
}

\author{
Sara Wilcox, Cheryl Der Ananian, \\ Patricia A. Sharpe, Jennifer Robbins, and Theresa Brady
}

Background: Physical activity (PA) is important for arthritis self-management. A better understanding of the PA correlates in persons with arthritis will help inform interventions. Methods: Computer searches were conducted on PubMed, PsychInfo, Current Contents, and Cinahl databases. Reference lists of extracted articles were also searched. Thirty-six studies published between 1976 and February 2004 met inclusion criteria. Results: PA correlates are presented for sociodemographic, psychological, health-related, social, and environmental categories. Self-efficacy, perceived benefits and barriers, mental well-being, prior PA, and pain received the most consistent support as PA correlates, whereas sociodemographic, social, and environmental variables were the least studied. Too few studies were conducted to allow comparisons across arthritis type or study design. Conclusions: We recommend that additional qualitative research be conducted to understand factors influencing PA in persons with arthritis. Prospective studies, particularly in the context of a PA program or intervention, would also be useful to better understand how barriers and enablers change over time.

Key Words: exercise, arthritis self-management, psychological factors, social factors, environmental factors

Regular physical activity (PA) is a crucial component of arthritis disease management. ${ }^{1-4}$ Specifically, both aerobic and resistance training among persons with arthritis delays disability; improves physical function, including postural and gait stability; promotes functional independence; improves quality of life, mental health, aerobic capacity, and muscle strength; and reduces pain..$^{3,5-7}$ The National Arthritis Action Plan ${ }^{8}$ emphasizes the importance of exercise as a self-management behavior, and Healthy People $2010^{9}$ underscores exercise as a method for achieving its national objective of reducing activity limitation.

Current PA recommendations for the general population encourage all adults to accumulate at least 30 min of moderate-intensity PA on most days of the week or at least $20 \mathrm{~min}$ of vigorous PA 3 or more $\mathrm{d} / \mathrm{wk} .{ }^{10}$ Despite the known health benefits

Wilcox, Der Ananian, Sharpe, and Robbins are with the University of South Carolina, Columbia, SC 29208. Brady is with the Centers for Disease Control and Prevention, Atlanta, GA 30341. 
of PA for people with arthritis, fewer people with arthritis meet these PA recommendations compared to people without arthritis ( $24.3 \%$ vs. $27.4 \%$, respectively $)^{11}$ and more are completely sedentary (31\% vs. $26 \%$, respectively). When interpreting these epidemiological data, it is important to note that there is evidence that people with rheumatoid arthritis and osteoarthritis can benefit from accumulating at least 30 min of moderate PA $3 \mathrm{~d} / \mathrm{wk}^{5,12}$

Because of the higher prevalence of inactivity among people with arthritis, and the known health benefits of PA for this population, health care and public health professionals need to understand the factors that influence people's participation in PA. This information can aid in the development of more tailored recruitment strategies and interventions. This article reviews studies that have examined the correlates of PA among people with arthritis. For the purpose of this review, we use a broad definition of arthritis, consistent with that outlined in the National Arthritis Action Plan. ${ }^{8}$

\section{Methods}

Computer searches were conducted using PubMed, PsychInfo, Current Contents, and Cinahl databases for articles prior to and including February 2004. Current Contents, however, was not available for searching at our institution after January 2003. Key words used to search these databases were: "arthritis," "osteoarthritis," "rheumatoid arthritis," "fibromyalgia," and "rheumatism," combined with the key words "exercise" or "physical activity." The three most common forms of arthritis (osteoarthritis [OA], rheumatoid arthritis [RA], and fibromyalgia [FM]) were used as search terms because of their proclivity, ${ }^{8}$ but other types of arthritis were not excluded. The bibliographies of all relevant articles (including review and consensus papers) were manually searched to identify additional articles. Finally, as part of our larger study, we conducted 2 teleconference discussions with 11 experts in the area of arthritis who were asked to forward relevant papers.

The following criteria were used to identify studies of arthritis and PA: (1) was conducted with adults ( $\geq 18 \mathrm{y}$ ), (2) was an intervention study, a cross-sectional or prospective study of the correlates of PA, or was a qualitative study of factors influencing PA, (3) was published in English, and (4) included a measure of PA (including, but not limited to, self-report scales of PA, PA logs or diaries, and measures of PA program attendance). Qualitative studies, while not required to have a measure of PA, had to ask participants questions about factors that influenced PA. Training studies and intervention studies that only examined physiological or functional outcomes were excluded.

\section{Results}

The initial literature searches yielded 4171 papers (1915 from PubMed, 2036 from Cinahl, 51 from Current Contents, and 169 from PsychInfo). A first screening excluded articles that were clearly unrelated to the review criteria (i.e., they did not focus on arthritis and exercise), retaining 240 potentially viable papers for more in-depth review. Of these 240 papers, 98 were excluded after reading the abstracts, and another 106 were excluded after reading the full article, for the following reasons: intervention or training studies that only included outcome data $(n=112)$, review papers $(n=55)$ or cross-sectional studies $(n=17)$ unrelated to 
correlates of PA, editorials or newsletters $(n=3)$, studies unrelated to PA or not specific to arthritis $(n=6)$, were consensus guidelines $(n=2)$, was a cost-benefit analysis of PA interventions $(n=1)$, and dissertations that could not be located $(n$ $=8$ ). Reference lists from review and consensus papers were reviewed.

Thirty-six studies from 1976 through February 2004 met the inclusion criteria. Of the studies, 7 were conducted with persons with OA (including 1 study in which $76 \%$ of the participants reported OA), 10 were with persons with RA (including 1 study in which $82 \%$ reported RA), 4 were with samples that were roughly evenly split between OA and RA, 8 were with persons with FM, 2 were with persons with ankylosing spondylitis (AS), and 5 either did not indicate the type of arthritis or included participants with various types of arthritis.

Nine of the studies conducted analyses in the context of a randomized clinical trial design or were follow-up studies to randomized clinical trials; 4 used a quasi-experimental design (pre-post); 2 used a prospective design; 17 used a crosssectional design; 1 used a retrospective design; and 3 were qualitative studies.

Certain terminology was used interchangeably across the studies by the study authors. To summarize multiple studies more succinctly, we used the term "physical activity," instead of "exercise" because exercise is a type of PA, and we used the term "adherence" instead of "compliance" because this term is more commonly used in the literature.

Table 1 summarizes our findings. Table 2 presents a summary of the populations, designs, and measures for all studies included in this review.

Table 1 Summary of Studies Reporting Positive, Negative, or No Associations With Physical Activity in People With Arthritis, by Arthritis Type

\begin{tabular}{|c|c|c|c|}
\hline & Positive association & Negative association & No association \\
\hline \multicolumn{4}{|l|}{ Sociodemographics } \\
\hline Age & OA: 18 RA: 19,20 & $\begin{array}{l}\text { OA: } 13,14 \text { FM: } 15 \\
\text { Unspecified: } \\
11,16,17\end{array}$ & $\begin{array}{l}\text { OA: } 21 \mathrm{FM}: 23 \\
\text { RA or OA: } 22\end{array}$ \\
\hline Education or income & $\begin{array}{l}\text { FM: } 15 \\
\text { Unspec: } 11,16,17\end{array}$ & OA: 18 & $\begin{array}{l}\text { OA: } 13,14,24 \\
\text { RA: } 19 \text { FM: } \\
15,23\end{array}$ \\
\hline Male gender & $\begin{array}{l}\text { RA: } 26 \\
\text { Unspec: } 11,16\end{array}$ & & $\begin{array}{l}\text { OA: } 14,18,21 \\
\text { RA: } 19,20\end{array}$ \\
\hline Being married & RA: 19 & RA: 27 Unspec: 16 & OA: 13,14 \\
\hline Caucasian race & Unspec: 11,17 & & OA: 18,21 \\
\hline Unemployment & FM: 15 & & RA: 20,26 \\
\hline $\begin{array}{l}\text { Psychological } \\
\text { Self-efficacy }\end{array}$ & $\begin{array}{l}\text { RA: } 27 \text { FM: } 15,30 \\
31,32 \text { AS: } 33 \\
\text { RA or OA: } 22,29\end{array}$ & & OA: 13 RA: 20 \\
\hline \multirow[t]{2}{*}{ Perceived benefits } & RA: $26,34,35,36$ & & RA: $19,20,37$ \\
\hline & RA or OA: 22,25 & & \\
\hline
\end{tabular}


Table 1 (continued)

\begin{tabular}{|c|c|c|c|}
\hline & Positive association & Negative association & No association \\
\hline Perceived barriers & & RA: 34 & $\begin{array}{l}\text { RA or OA: } \\
22,25\end{array}$ \\
\hline Well-being (or QOL) & $\begin{array}{l}\text { OA: } 13 \text { RA: } 20 \\
\text { FM: } 32\end{array}$ & & \\
\hline Depression & & $\begin{array}{l}\text { OA or RA: } 44 \\
\text { FM: } 15,23 \\
\text { Unspec: } 16\end{array}$ & $\begin{array}{l}\text { OA: } 13,21 \\
\text { FM: } 45\end{array}$ \\
\hline Anxiety & & OA or RA: 44 & FM: 45 \\
\hline $\begin{array}{l}\text { Personality } \\
\text { Extraversion }\end{array}$ & OA: 13 & & \\
\hline Helplessness & & OA: 13 & \\
\hline Other variables & & & OA: 13 \\
\hline Prior PA & $\begin{array}{l}\text { OA: } 21 \text { RA: } 27,46 \\
\text { FM: } 15 \text { AS: } 33 \\
\text { OA or RA: } 44\end{array}$ & & RA: 20 \\
\hline $\begin{array}{l}\text { Health-related } \\
\quad \text { Pain }\end{array}$ & OA: 24 & $\begin{array}{l}\text { RA: } 20 \text { FM: } 23 \\
\text { OA or RA: } 44 \\
\text { Unspec: } 16\end{array}$ & $\begin{array}{l}\text { OA: } 21 \text { RA: } 26 \\
\text { FM: } 15 \text { OA or } \\
\text { RA: } 25\end{array}$ \\
\hline $\begin{array}{l}\text { Disease severity, } \\
\text { duration, or } \\
\text { disability }\end{array}$ & OA: 24 FM: 23 & $\begin{array}{l}\text { OA: } 14 \text { RA: } 20 \\
\text { FM: } 23 \\
\text { OA or RA: } 22,25 \\
\text { Unspec: } 16\end{array}$ & $\begin{array}{l}\text { RA: } 19,26,35 \\
\text { OA: } 21 \text { FM: } 30\end{array}$ \\
\hline $\begin{array}{l}\text { Perceived health } \\
\text { status }\end{array}$ & $\begin{array}{l}\text { OA: } 13 \text { FM: } 32 \\
\text { Unspec: } 16\end{array}$ & & $\begin{array}{l}\text { FM: } 15 \text { OA or } \\
\text { RA: } 25\end{array}$ \\
\hline Stiffness & & & RA: 26,36 \\
\hline Fatigue & & FM: 23,47 & RA: 26 \\
\hline Body-mass index & & Unspec: 11,16 & OA: 13,21 \\
\hline Social support & $\begin{array}{l}\text { RA: } 26,36 \\
\text { OA or RA: } 44\end{array}$ & & $\begin{array}{l}\text { RA: } 19,35,36 \\
\text { OA: } 14,21 \\
\text { FM: } 15\end{array}$ \\
\hline \multicolumn{4}{|l|}{ Environmental factors } \\
\hline Rural residence & RA: 26 & & \\
\hline
\end{tabular}

Note: Many qualitative studies included in this article described benefits and barriers most commonly reported by people with arthritis. These variables cut across many of the categories listed above but are not included in this table because they were not examined as correlates of physical activity. AS, ankylosing spondylitis; FM, fibromyalgia; OA, osteoarthritis; RA, rheumatoid arthritis; Unspec, arthritis type was not specified. 


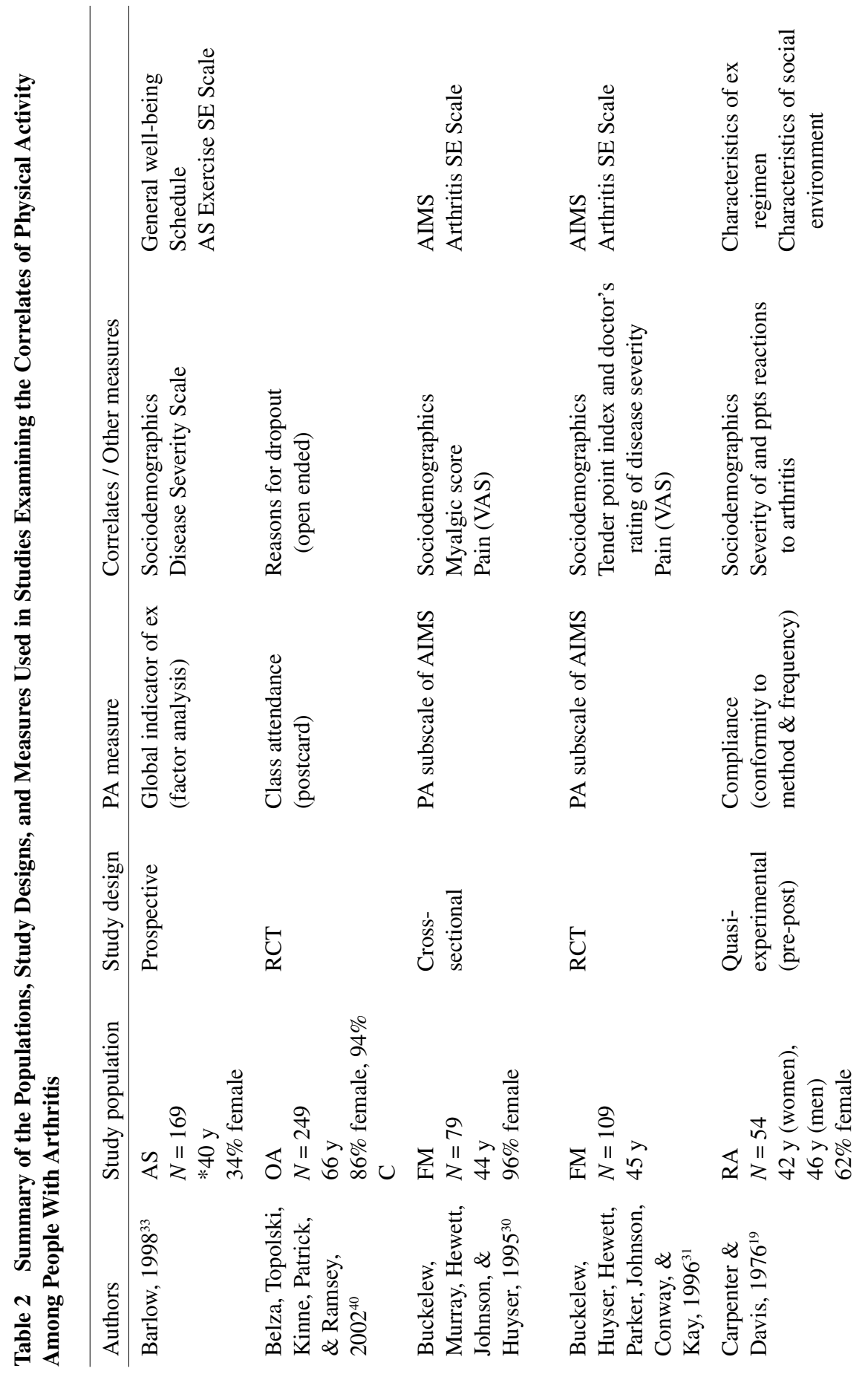



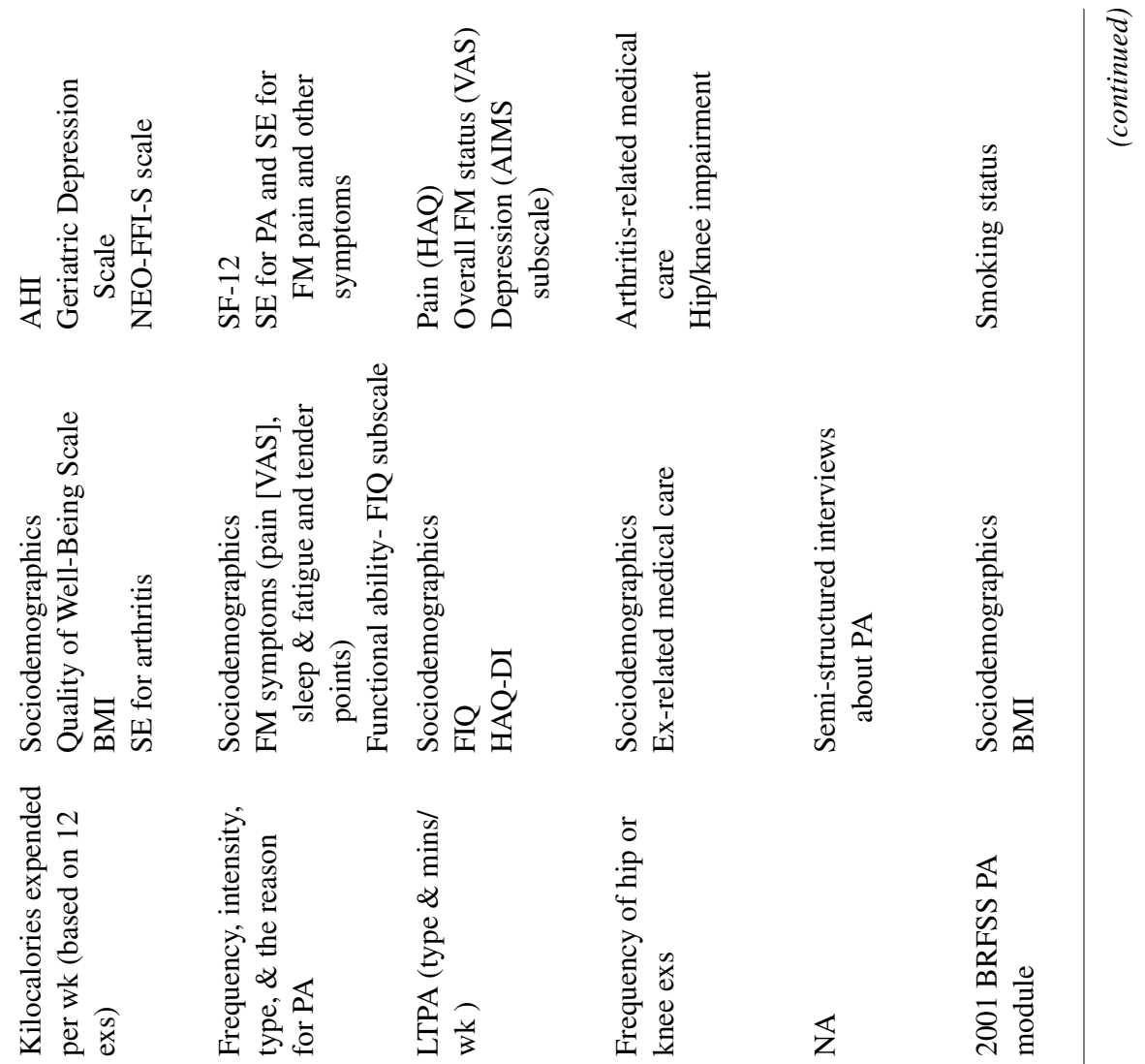

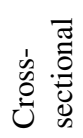
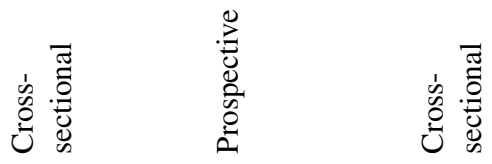

㤩

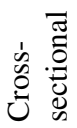

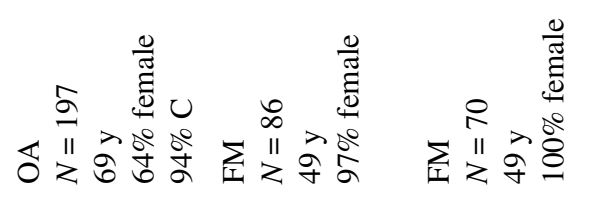

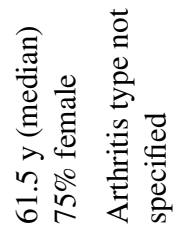

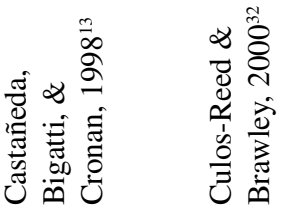

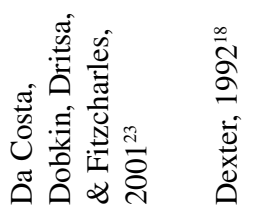

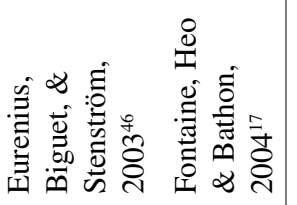




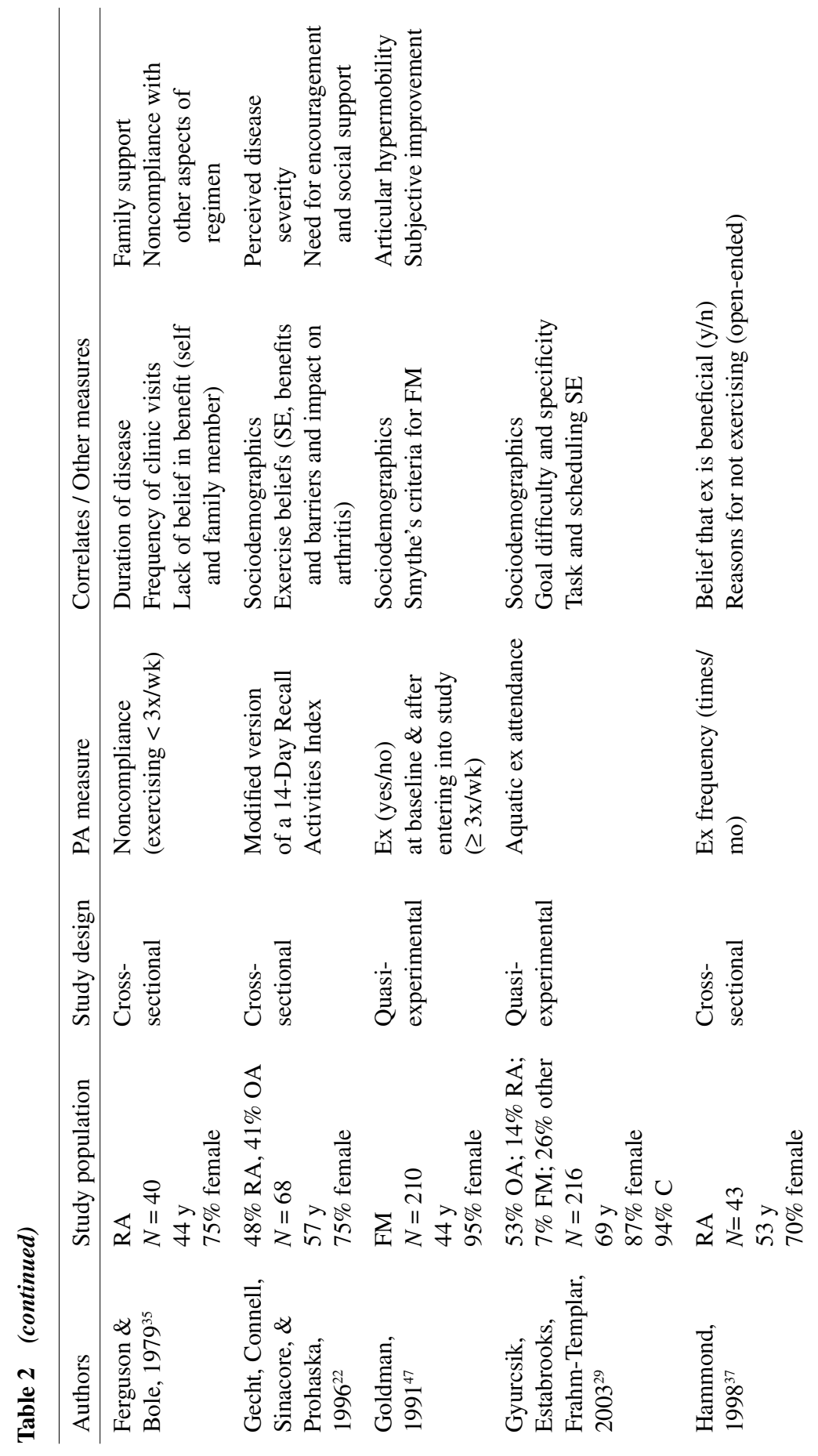



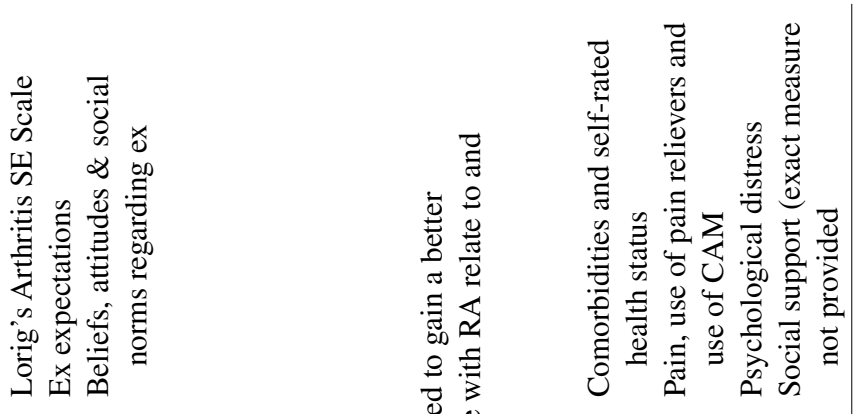

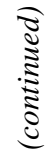
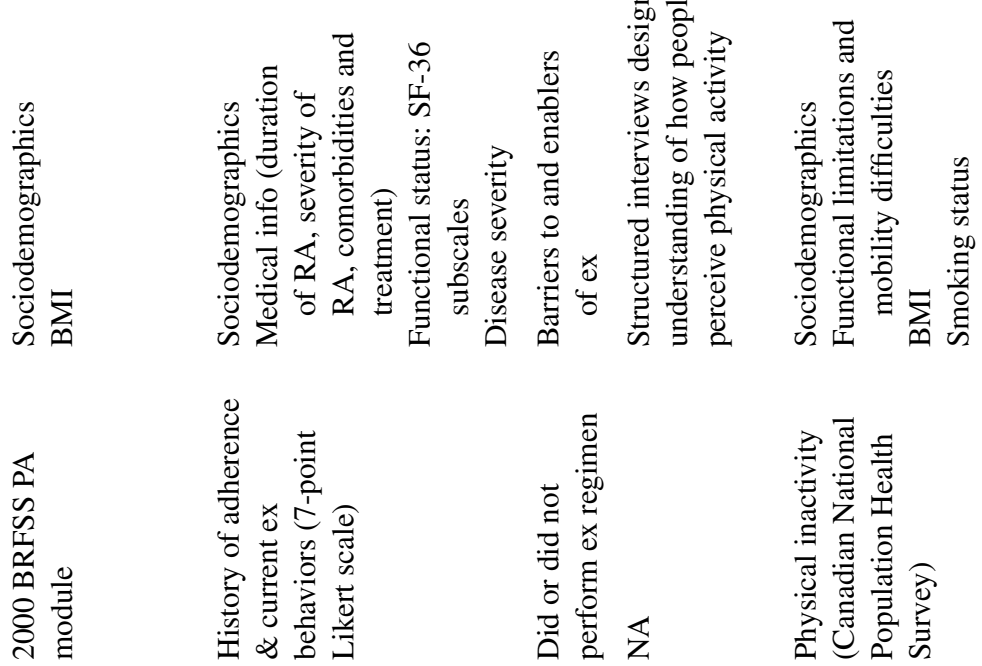

ì

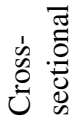

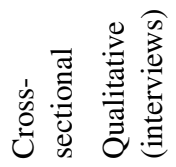

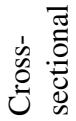

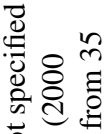
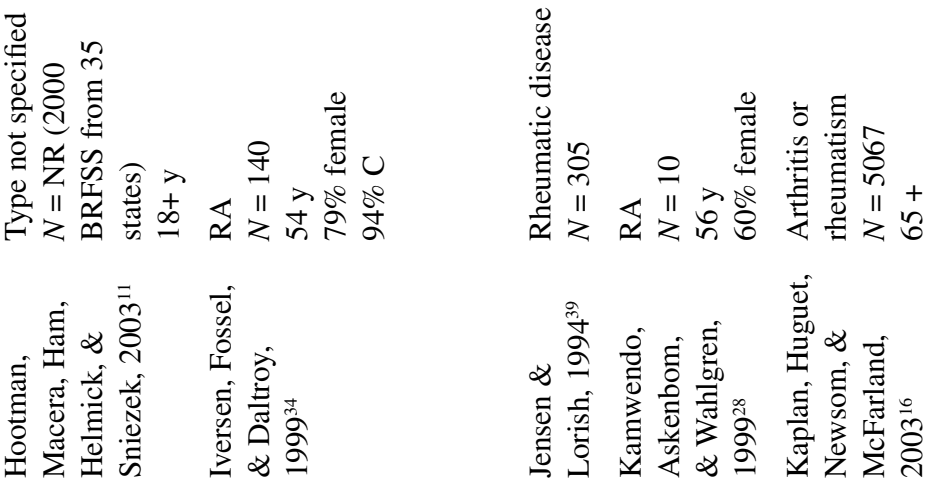


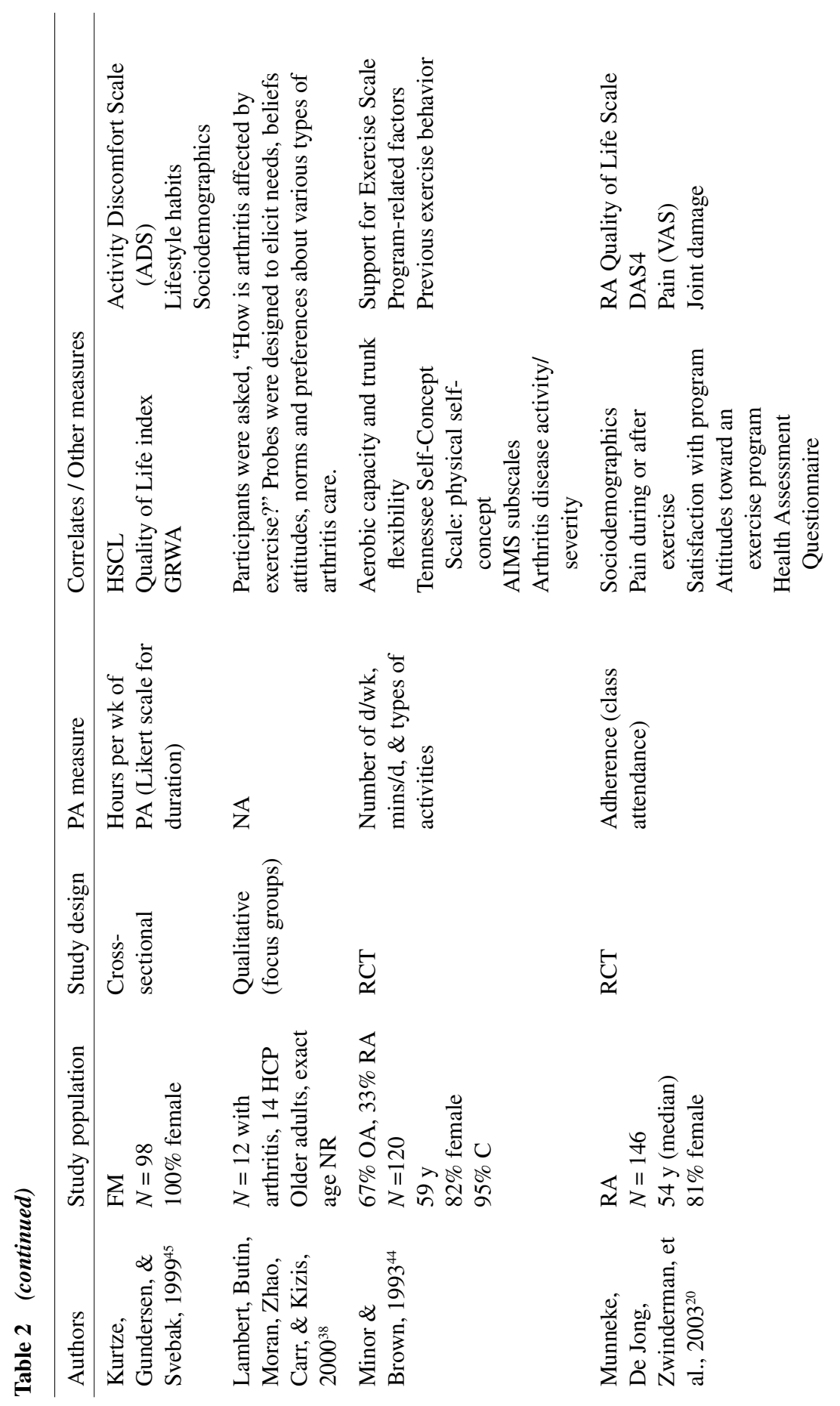




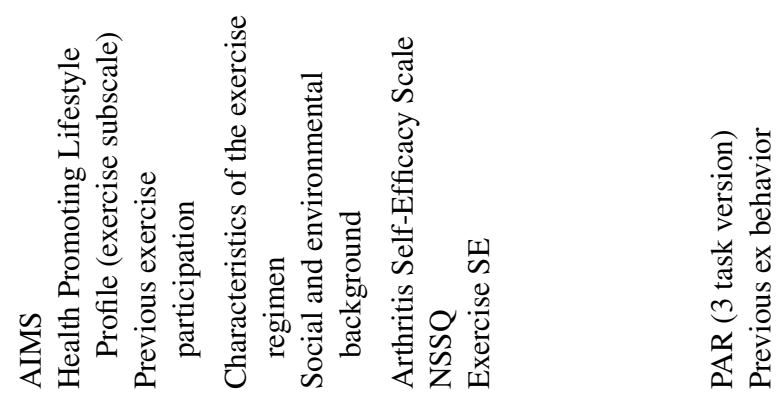

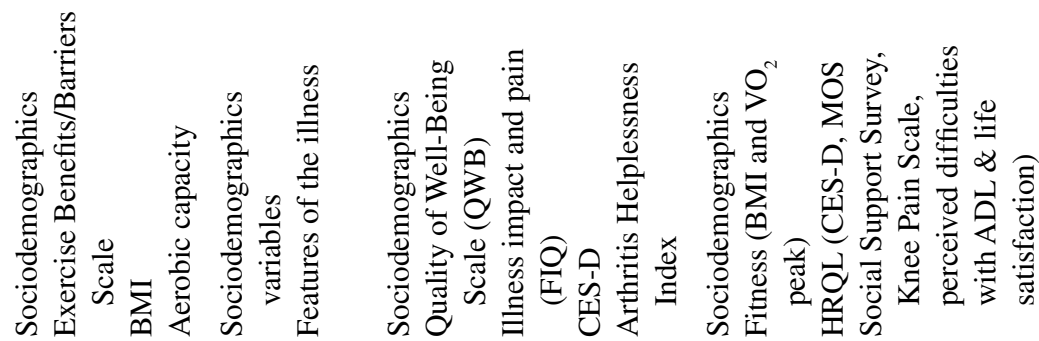

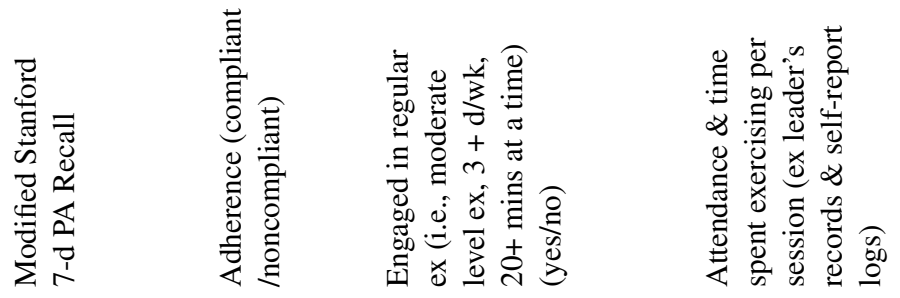

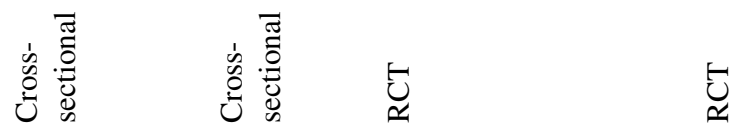

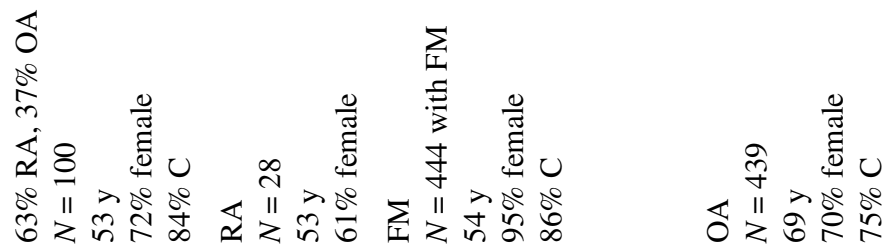

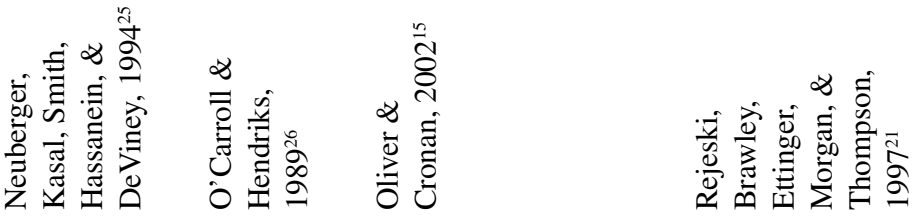




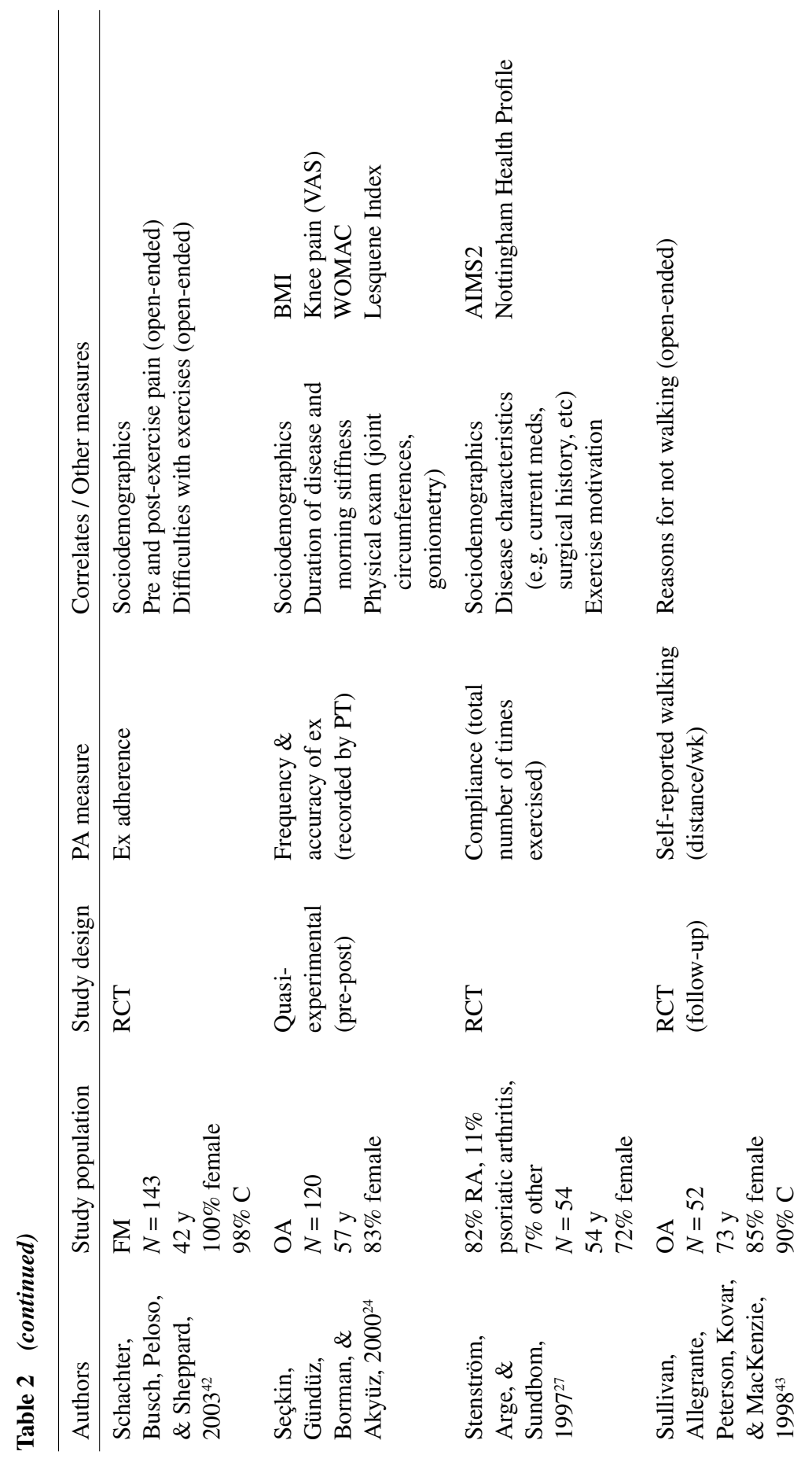



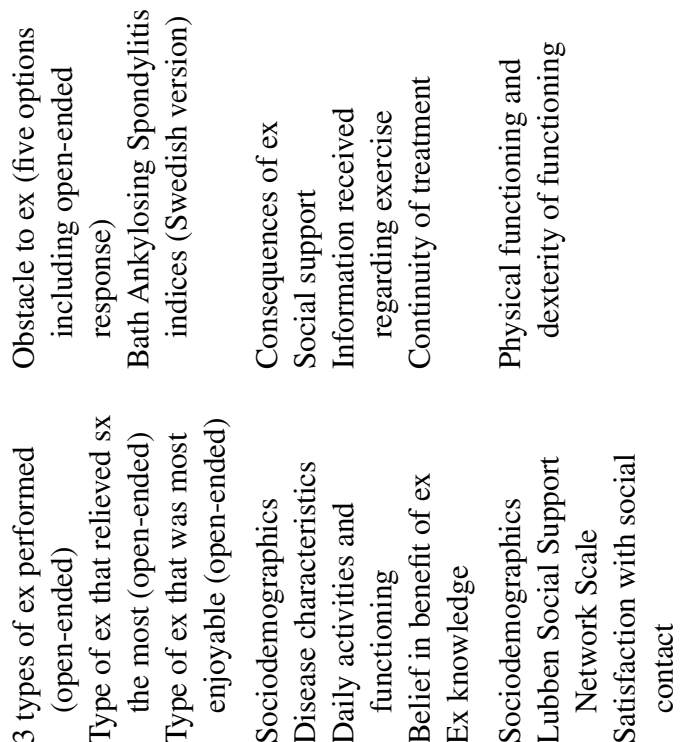

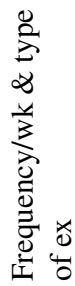
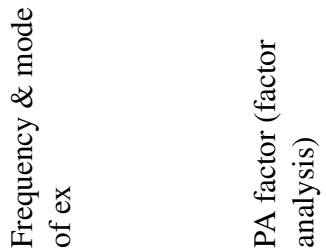

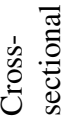

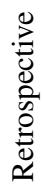

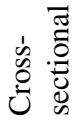

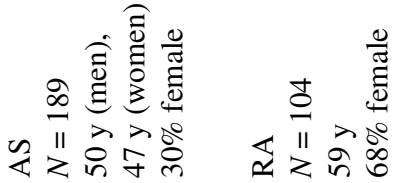

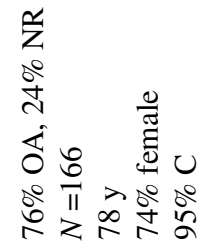

छี

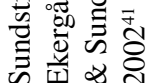

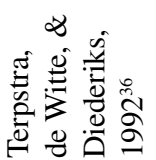

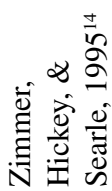

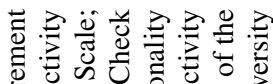

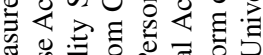
ฮै :

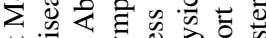

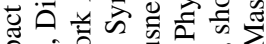

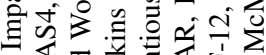

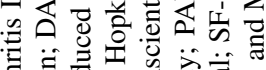

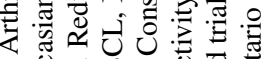

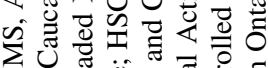

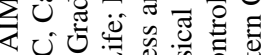

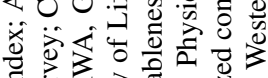

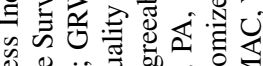

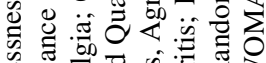
बै

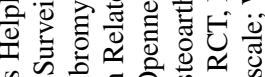

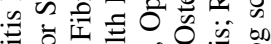

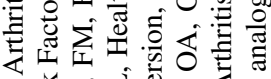

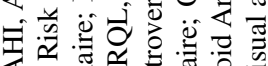

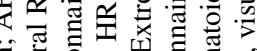

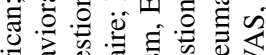
氠

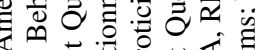

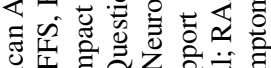

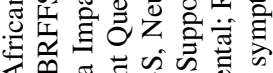

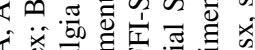

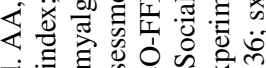
d

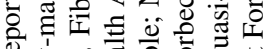

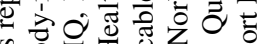

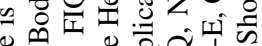

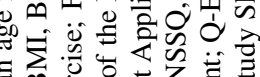

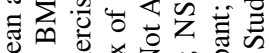

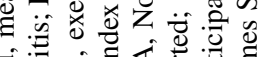

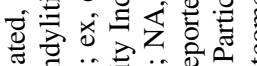

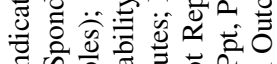

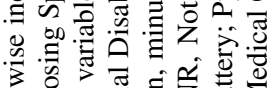

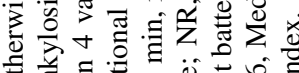

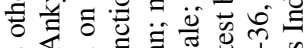
D.
s. 


\section{Sociodemographic Correlates}

The most commonly studied sociodemographic correlates of PA among people with arthritis were age, education level, income, gender, and marital status. A smaller number of studies examined race and employment status.

Age. Age was assessed in 12 of the studies, and its association with PA was inconsistent. Age was negatively associated with PA in 5 studies: 2 studies of $\mathrm{OA},{ }^{13,14} 1$ of $\mathrm{FM},{ }^{15}$ and 3 in which the type of arthritis was unspecified. ${ }^{11,16,17}$ Age was positively associated with PA in 3 studies: $1 \mathrm{OA}^{18}$ and 2 RA. ${ }^{19,} 20$ Age was unrelated to PA in 3 additional studies: 1 of $\mathrm{OA},{ }^{21} 1$ with participants with either RA or OA, ${ }^{22}$ and 1 of FM. ${ }^{23}$

Education and Income. Education level was assessed in 10 studies, and income was assessed in 5 studies. Education level was unrelated to PA in 6 of the 10 studies: 3 studies of OA, ${ }^{13,14,24} 1$ of RA, ${ }^{19}$ and 2 of FM. ${ }^{15,23}$ Income was unrelated to PA in 4 of the 5 studies: 2 of OA, ${ }^{13,14} 1$ of RA, ${ }^{19}$ and 1 of FM. ${ }^{23}$ Several studies, however, reported significant relationships. Oliver and Cronan found that in participants with FM, having a high school education or less was associated with lower levels of PA at their 12-month assessment (but was unrelated at baseline, 6-, and 18-month assessments). ${ }^{15}$ In 3 studies in which arthritis type was not specified, those with lower levels of education also had lower rates of PA. ${ }^{11,16,17}$ Consistent with these associations, Neuberger and colleagues found that among participants with RA or OA, those with lower levels of education and lower income levels reported greater barriers to exercise. ${ }^{25}$ In 1 study of OA, having a higher level of education was associated with lower levels of PA. ${ }^{18}$

Gender. Gender was examined in 8 studies, although it is notable that women tended to comprise the majority of participants in studies of arthritis, particularly in studies of FM. Gender was not associated with PA in 5 of the 8 studies: 3 studies of $\mathrm{OA}^{14,18,21}$ and 2 of RA. ${ }^{19,20}$ In the remaining 3 studies, men had higher rates of PA than women; these studies included populations with $\mathrm{RA}^{26}$ and 2 studies in which the arthritis type was not specified. ${ }^{11,16}$

Marital Status. Marital status was assessed in 5 studies, with inconsistent results. Marital status was unrelated to PA in 2 OA studies. ${ }^{13,14}$ In 1 study of RA, there was a trend for those who were married to have higher rates of adherence than those who were not married (i.e., widowed, single, divorced). ${ }^{19}$ In 2 studies, however, there was an inverse relationship between marital status and PA such that married adults reported lower PA levels than adults who were not married: 1 study of $\mathrm{RA}^{27}$ and another study in which the arthritis type was not assessed (this relationship was only seen in men). ${ }^{16}$

Race. Most studies included a majority of Caucasian participants. In the 2 studies of OA in which race was examined, no significant association with PA was found. ${ }^{18,21}$ In 2 national samples of persons with arthritis (type unspecified), African Americans and Hispanics had among the lowest rates of participation in regular PA relative to Caucasians. ${ }^{11,17}$

Employment Status. Employment status was assessed in 4 studies. Among persons with FM, being unemployed was associated with higher levels of PA at the baseline assessment but not at the 6-, 12-, or 18-month follow-up in an intervention 
study. ${ }^{15}$ Consistent with this association, a qualitative study of people with RA found that being employed was perceived as a barrier to PA. ${ }^{28}$ In the other 2 studies in which employment status was assessed, however, it was unrelated to PA among participants with RA..$^{20,26}$

\section{Psychological and Behavioral Correlates}

The most commonly studied psychological and behavioral correlates were selfefficacy, perceived benefits (also called outcome expectations), perceived barriers, mental health factors (e.g., depression, anxiety, quality of life), personality characteristics, and past PA behavior.

Self-efficacy. Ten studies examined the association between self-efficacy and PA, and most found that higher levels of self-efficacy were associated with greater PA. In 1 study of people with $\mathrm{RA}^{27}$ and in 2 studies that had a combined sample of people with either RA or OA, ${ }^{22,}{ }^{29}$ higher self-efficacy for PA was associated with greater adherence rates. Similarly, 4 studies of people with FM reported that selfefficacy (including self-efficacy for PA, pain, function, or controlling arthritis) was associated with higher levels of PA. ${ }^{15}, 30-32$ Barlow found that self-efficacy for PA was associated with PA both at baseline and at 6 months follow-up among people with AS. ${ }^{33}$ Only 2 studies reported a lack of association between self-efficacy and PA: one with a sample of persons with OA (self-efficacy for arthritis management), ${ }^{13}$ and the second in a sample of persons with RA (self-efficacy for PA). ${ }^{20}$

Perceived Benefits. Nine studies examined the relationship between perceived benefits (or outcome expectations) and PA, and another 3 studies examined in a descriptive or qualitative way the types of benefits that were most commonly reported by persons with arthritis. Among people with RA, 4 studies showed that perceived benefits and positive attitudes regarding PA were associated with higher levels of PA, ${ }^{26,34-36}$ although 3 studies reported no association. ${ }^{19,}{ }^{20,37}$ Among 2 studies in which participants had either OA or RA, a positive association between perceived benefits and PA was reported. ${ }^{22,25}$

Qualitative and descriptive studies have provided useful information regarding the benefits that are most meaningful to persons with arthritis. Kamwendo and colleague's in-depth interviews with adults with RA found that major motivations for PA were positive physical outcomes, such as strength, aerobic capacity, mobility, and decreased pain and stiffness; positive psychological outcomes; and social benefits. ${ }^{28}$ In this same study, fear of losing mobility was also a major motivator. Lambert and colleagues found that people with arthritis (type unspecified) believed that PA not only was important for the treatment of their arthritis but also helped them to get their minds off of their pain. ${ }^{38}$ Consistent with these findings, Jensen and Lorish reported that the most common reasons cited for being active among persons with arthritis (type unspecified) included feeling better, making joints feel better, being able to perform other tasks more easily, feeling more in control, and attempting to please important others. ${ }^{39}$

Perceived Barriers. Three studies examined the relationship between perceived barriers and PA, and 12 studies described the barriers to PA or the most common reasons for drop-out among persons with arthritis. One of the 3 studies found that among adults with RA, perceiving greater barriers to PA were associated with lower 
levels of PA. ${ }^{34}$ Two studies that included a sample of adults with either RA or OA found that barriers to PA were unrelated to actual PA. ${ }^{22,25}$

Perceived barriers to PA have typically included individual, social, and environmental barriers. Across arthritis types, there were a number of overlapping barriers. First, in terms of individual-level perceived barriers to PA, lack of time or the perception of being too busy was cited by people with $\mathrm{OA},{ }^{40} \mathrm{RA},{ }^{28,34,37}$ and $\mathrm{AS},{ }^{41}$ and in a combined sample of adults with RA or OA. ${ }^{25}$ People with FM ${ }^{42}$ and RA, ${ }^{34}$ and those from studies in which arthritis type was unspecified ${ }^{39}$ cited boredom as a barrier to PA. Negative perceptions of PA or lack of knowledge regarding PA was cited in people with $\mathrm{RA}^{37}$ and in samples of unspecified/combined arthritis. ${ }^{25,38,39}$ Arthritis-related symptoms such as pain and fatigue were cited as barriers among people with $\mathrm{OA},{ }^{40,43} \mathrm{RA},{ }^{27,} 28,34,37 \mathrm{FM},{ }^{42}$ and $\mathrm{AS},{ }^{41}$ and in a population in which arthritis type was unspecified. ${ }^{39}$ Having other comorbid conditions was raised as a barrier by people with $\mathrm{OA}^{40}$ and RA. ${ }^{20,27}$ Other less commonly cited personal barriers to PA were personal problems (OA), ${ }^{40}$ lack of motivation (RA), ${ }^{37}$ and not having privacy to perform PA $(\mathrm{FM}){ }^{42}$

Lack of encouragement to be physically active from important others (e.g., family, friends, health care providers) was cited as a social barrier to PA among people with $\mathrm{RA}^{28}$ and in a combined sample of adults with RA or OA. ${ }^{25}$

In terms of environmental barriers, factors related to facilities, such as being too far away or inconvenient to access were cited as barriers to PA by people with $\mathrm{OA}^{40}$ and $\mathrm{AS}^{41}$ and in a combined sample of adults with RA or OA. ${ }^{25}$ Weather was also cited by people with $\mathrm{OA}^{43}$ and $\mathrm{RA}^{28}$ as a barrier. Finally, in a sample of adults with AS, financial constraints were cited as a barrier to PA. ${ }^{41}$

Mental Health Factors. Mental health variables were addressed in 9 studies, of which 7 reported significant associations. Greater well-being or quality of life was associated with higher levels of PA in 1 study of OA, ${ }^{13} 1$ study of RA, ${ }^{20}$ and another study of FM. ${ }^{32}$ Kaplan and colleagues found that in a sample of Canadian adults, psychological distress was negatively related to PA in men (but not in women) who had arthritis (type not specified). ${ }^{16}$ In 2 studies of individuals with FM, depression was associated with lower levels of PA during at least one of their assessments. ${ }^{15,23}$ In a combined sample of people with either OA or RA, baseline depression and anxiety were associated with lower levels of PA 3 months later. ${ }^{44}$ In addition, improvements in depression predicted higher levels of PA both 3- and 9-months later. Depression, however, was unrelated to PA in 2 studies of OA, ${ }^{13,21}$ and both anxiety and depression were unrelated to PA in another study of women with FM. ${ }^{45}$

Personality. One study examined the association between personality and PA in adults with $\mathrm{OA}$ and found that extraversion was positively associated, helplessness was negatively associated, and other personality variables (neuroticism, agreeableness, openness, and conscientiousness) were unrelated to PA. ${ }^{13}$

Behavioral Factors. Prior PA was positively associated with current PA in 6 of 7 studies: 1 study of OA, ${ }^{21} 2$ studies of RA, ${ }^{27,} 461$ study that included adults with either OA or RA, ${ }^{44} 1$ study of FM, ${ }^{15}$ and 1 study of adults with AS. ${ }^{33}$ Among the studies that examined prior PA behavior, only 1 study in adults with RA detected no association between prior activity and attending a multicomponent exercise program (i.e., strength, aerobic, and flexibility) over a 2 -y period. ${ }^{20}$ 


\section{Health-Related Correlates}

Summarizing the health-related correlates of PA in persons with arthritis is challenging. A large number of measures and constructs are used, and they vary greatly from study to study. Thus, this section summarizes only those factors that were most commonly reported. It is also important to note that some variables-such as pain, fatigue, impact of illness, and self-related health—are likely influenced by psychosocial factors.

Pain. As previously noted, pain is a commonly cited barrier to PA among persons with $\mathrm{OA},{ }^{40,43} \mathrm{RA},{ }^{28,34,37}$ and $\mathrm{FM},{ }^{42}$ as well as in samples in which arthritis type is not specified..$^{39}$ Although pain is a commonly cited reason for not being physically active or for dropping out of a program, the actual association between pain and PA has been less consistent. Four studies found that pain was associated with lower levels of PA. In 1 study of adults with RA, greater pain level and greater frequency of pain episodes were associated with lower levels of PA. ${ }^{20}$ Severe pain was associated with lower levels of PA in a large sample of adults with arthritis (type unspecified). ${ }^{16}$ Minor and colleagues reported that improvements in pain were associated with greater PA at the 18-month follow-up assessment among participants with OA or RA. ${ }^{44}$ DaCosta and colleagues also reported that pain was negatively related to PA at the 3-y follow-up assessment (but not at baseline) for people with FM. ${ }^{23}$ Four other studies, however, reported no association between pain and PA: 1 study of $\mathrm{OA},{ }^{21} 1$ of RA,${ }^{26} 1$ combined sample study, ${ }^{25}$ and 1 of FM. ${ }^{15}$ Finally, Seckin and colleagues found that persons with OA who reported greater pain actually engaged in more frequent exercise in a physical therapy context. ${ }^{24}$

Disease Severity. Studies that have attempted to address disease severity or health status have produced mixed findings. These studies have typically examined disease duration, disease severity (self- or physician-reported), self-reported health status, disability status, fitness, and symptoms that might be indicative of severity (e.g., fatigue, stiffness).

Six studies examined disease duration. In one prospective study of FM, longer disease duration was associated with lower levels of PA at the 3-y follow-up (but not at baseline). ${ }^{23}$ In a combined sample of persons with RA or OA, disease duration was related to higher perceived barriers to PA. ${ }^{25}$ In other studies, however, including 2 of $\mathrm{RA}^{26,35}$ and 1 of $\mathrm{FM},{ }^{30}$ no association was found between disease duration and PA. In addition, in 1 study of OA in a physical therapy context, longer disease duration was related to higher levels of PA. ${ }^{24}$

Among the 5 studies that assessed disease severity via self-reports or physician-reports, 3 found it to be negatively related to PA, including 1 study of RA, ${ }^{20} 1$ study of a combined sample of RA and OA,,${ }^{22}$ and 1 of FM. ${ }^{23}$ Disease severity, however, was unrelated to PA in 2 studies of RA. ${ }^{19,26}$

Among the 5 studies that examined perceived health status, this variable was positively associated with PA in 3 of the studies; 1 of OA (Quality of Well-Being Scale, QWB), ${ }^{13} 1$ of FM (physical and mental subscales of SF-12), ${ }^{32}$ and 1 of unspecified arthritis in women only (4-point self-rated health scale). ${ }^{16}$ Perceived health status, however, was unrelated to PA in a sample of adults that had OA or RA (4-point self-rated health scale) ${ }^{25}$ and in a sample of adults with FM (QWB scale). ${ }^{15}$ 
In 4 studies, disability was associated with lower levels of PA, including 1 study of OA, ${ }^{14} 1$ of RA, ${ }^{20} 1$ of FM, ${ }^{23}$ and 1 of an unspecified arthritis. ${ }^{16}$ Disability was unrelated to PA, however, in 1 study of older adults with OA. ${ }^{21}$

In Minor et al.'s study of persons with OA or RA, higher levels of baseline fitness were associated with higher PA at baseline and at 18 months follow-up. ${ }^{44}$ Fitness was unrelated to PA in a study of OA and older adults. ${ }^{21}$

Symptoms that might be indicative of greater disease severity have also been examined in 8 studies. Stiffness was unrelated to PA in 2 studies of RA ${ }^{26,36}$ but was cited as a reason for dropping out of a program among people with FM. ${ }^{42}$ In a prospective study of FM, fatigue was predictive of PA at the 3-y follow-up assessment, although it was unrelated at baseline. ${ }^{23}$ Morning fatigue was also related to lower levels of PA in another study of FM. ${ }^{47}$ Furthermore, fatigue was cited as a barrier to PA in populations with RA, ${ }^{28} \mathrm{FM},{ }^{42} \mathrm{AS},{ }^{41}$ and an unspecified type of arthritis. ${ }^{39}$ One study, however, reported no association between fatigue and PA among people with RA. ${ }^{26}$

Body-Mass Index. Five studies examined body-mass index (BMI) in relation to PA. Greater BMI was associated with inactivity in 2 studies where arthritis type was not specified, ${ }^{11,16}$ and greater BMI was associated with higher perceived barriers to PA in a sample of adults with either OA or RA. ${ }^{25}$ Obesity was unrelated to PA, however, in 2 studies of OA. ${ }^{13,21}$

\section{Social Correlates}

Eight studies examined the relationship between social support and PA, and two additional studies reported that participants spontaneously raised social support as a factor in their PA or adherence. Studies that used a PA-specific measure of social support were more likely to find an association with PA than studies that used generic measures of social support (e.g., social network size). Family encouragement of a PA program was related to adherence in a sample of adults with RA. ${ }^{26}$ Receiving information from health professionals (informational support) was related to higher levels of PA among adults with RA, but social support from family was unrelated in this sample. ${ }^{36}$ Among adults with either OA or RA, social activity during the exercise class was related to PA at a 3-month follow-up assessment, and friend support for PA was related to PA at a 9-month follow-up assessment. ${ }^{44}$ In 5 studies, however, various measures of social support were unrelated to PA. Social support (generic measure) was unrelated to PA in OA, ${ }^{21}$ as was extent of social network and satisfaction with social contact. ${ }^{14}$ Family understanding of and assistance with PA was unrelated to PA in adults with RA, ${ }^{19}$ as was family support and knowledge (related to disease rather than PA). ${ }^{35}$ In a study of adults with FM, satisfaction with social support and size of support network were unrelated to PA. ${ }^{15}$

In 2 studies, participants identified social factors as influential in their PA. Kamwendo and colleague's qualitative study of adults with RA found that encouragement for PA from health professionals, family, and friends was perceived as a major motivator for PA, whereas "over-protection" by friends and family and lack of instruction from a health care provider were seen as major barriers to PA. ${ }^{28}$ Lack of support from family was also identified as a significant barrier to PA among a sample of adults with either OA or RA. ${ }^{25}$ 


\section{Environmental Correlates}

Few studies have examined environmental correlates of $\mathrm{PA}$ in persons with arthritis. Aspects of activity facilities (e.g., inconvenient, inaccessible, too far away) were cited by study participants as a reason for dropping out of a program or as a barrier to PA participation among adults with $\mathrm{OA},{ }^{40}$ a sample of adults with either OA or $\mathrm{RA},{ }^{25}$ and a sample of adults with AS ${ }^{41}$ Living in a rural area was associated with higher adherence in 1 study of adults with RA. ${ }^{26}$ Finally, bad weather was cited as a barrier to PA among adults with $\mathrm{OA}^{43}$ and RA. ${ }^{28}$

\section{Discussion}

We reviewed 36 studies that examined correlates of PA among people with OA, RA, FM, AS, and unspecified arthritis. Sociodemographic, psychological, health-related, social, and environmental correlates were reviewed for each type of arthritis.

In contrast to the literature of PA correlates for the adult general population, ${ }^{48}$ sociodemographic variables were not consistently studied as correlates of PA in people with arthritis, and when they were studied, few were significant. The lack of associations in our review could be explained by several factors. First, samples tended to be homogeneous. For example, studies of OA often focused on older Caucasian adults, whereas most FM studies included middle-aged women. This restriction in range might have limited the ability to find significant correlations. It is also possible that other variables are more important for predicting PA in persons with arthritis, including disease severity, pain, and limitations in mobility.

Across studies, the most commonly examined psychological variables were self-efficacy, perceived benefits and barriers, and mental well-being. In general, each of these variables were significant correlates of PA or adherence, consistent with the larger body of research focused on PA correlates.$^{48}$ It is important to note, however, that null findings were somewhat common, and might be explained by many factors, including lack of statistical power and differing measurement tools. In addition, symptoms such as pain, fatigue, and stiffness might not pose as barriers until a person attempts a PA program. Although many of the PA barriers in persons with arthritis were similar to general adult populations (e.g., lack of time), other barriers were clearly unique to this population (e.g., pain, fatigue, stiffness). These factors could be important mediating variables in intervention studies. Indeed, Rejeski and colleagues $^{49}$ found that those with greater knee pain and lower self-efficacy were less likely to achieve positive outcomes in an exercise intervention.

Social variables were studied less often than psychological variables. Several studies found that support from family, friends, and health care providers related to higher PA or adherence. This relationship was not as consistent as would be expected from the general adult population, however. ${ }^{48}$ It is likely that social support operates in a more complex way in disease states. For example, in one qualitative study, ${ }^{28}$ participants discussed how overprotective family members, in an attempt to be supportive, actually interfered with PA. In addition, in all but 1 study that reported no association, generic measures were used.

Pain was consistently associated with lower PA and adherence across arthritis types. This finding is paradoxical. A substantial number of controlled, randomized trials of exercise in persons with arthritis have reported modest reductions in pain 
over time (4 to 18 months). ${ }^{5,12,50}$ It is plausible that perceptions of pain, either by themselves or in combination with poor self-efficacy or depression, might cause an individual to stop PA before the benefits of pain reduction are realized. In one intervention study, ${ }^{44}$ improvements in pain were found to predict subsequent PA, suggesting that this outcome could be critical for people with arthritis for adherence to a PA program.

\section{Limitations of This Literature Review}

Although we used standard approaches to search the literature, it is possible that relevant articles not included in these databases were omitted. In addition, many of the studies included were not designed to examine correlates of PA. We chose to be inclusive because this literature is small, and these studies provided information that might be useful in understanding factors that influence PA in people with arthritis. Many studies included small samples and might have been underpowered to detect associations. In addition, we included studies that varied considerably in the choice of measures, making it challenging to compare study results. Finally, because of the relatively small number of studies overall and the diverse populations included, we are not able to comment on how study designs might have impacted findings.

\section{Recommendations for Future Research}

Relatively little is known regarding factors that influence PA in persons with arthritis. In fact, too few studies have been conducted to allow us to make comparisons across arthritis types or to compare factors associated with aerobic versus strengthtraining activities. We conclude this article by making recommendations for future research in this area.

First, more qualitative studies should be conducted to understand PA barriers, enablers, and motivators among people with arthritis. In-depth interviews and focus groups can be particularly useful when studying populations that have received little study because they allow one to learn what is most important to the individual, rather than imposing beliefs on the population. Age, gender, arthritis type, socioeconomic status, race/ethnicity, and PA level are likely to be important variables on which to stratify in qualitative studies. To date, qualitative studies in this area have included very small samples, ranging from 12 to 16 participants. ${ }^{28,38,46}$

Second, we recommend that prospective studies be conducted to examine temporal relationships between potential correlates and PA. PA-specific measures for variables such as self-efficacy and social support are recommended. These studies should be adequately powered to allow subgroup analyses, and should use reliable and valid measures of PA. An example of this type of research is a study by Minor and Brown, in which they were able to examine whether changes in variables predicted subsequent PA. ${ }^{44}$ Studies might benefit from explicitly testing whether variables such as self-efficacy, outcome expectations, and pain are mediators of treatment effects. ${ }^{49,51}$ Additional studies using experimental design might also help to explain at what point in the behavior change process variables exert their influence. ${ }^{52}$ For example, Oliver and Cronan ${ }^{15}$ found that the same variables had different associations with physical activity over the course of an 18-month study. One could imagine how specific symptoms might not show an association 
with PA in a generally underactive sample, whereas these symptoms could be important once a person begins to adopt PA, and still other symptoms and barriers might be particularly relevant in the maintenance phase.

Finally, the context of the intervention is important to consider in future studies. For example, a study done in the context of physical therapy found that greater pain and longer disease duration were associated with greater compliance to exercise therapy ${ }^{24}$ Individuals who seek out therapy and are experiencing greater distress could be more likely to comply with treatment, whereas in the larger general population of people with arthritis, these factors might be barriers to PA.

\section{Conclusions}

In summary, correlates of PA in persons with arthritis should be explored in greater detail for at least 2 reasons. First, understanding the correlates of PA helps identify subgroups who experience particularly low rates of PA..$^{53}$ This information can be used to help allocate resources toward PA promotional activities and can help to inform the content of these activities. Second, understanding mutable correlates of PA is useful for designing targeted PA educational campaigns, recruitment campaigns, and interventions. ${ }^{53}$ Our findings suggest that interventions should focus on increasing knowledge of the benefits of PA with arthritis (particularly pain reduction and disability prevention), targeting and reducing barriers, increasing self-efficacy, and working with families and health care providers to provide PA support. Additional research is needed, however, to more fully understand the relationships between these variables and PA across arthritis types and the role these variables play in the context of PA interventions.

\section{Acknowledgments}

This project was funded by a grant from the US Centers for Disease Control and Prevention (CDC) and the Association of Schools of Public Health, project \#S2109-22/22. The views expressed in this article are not the official views of the CDC or the Association of Schools of Public Health.

\section{References}

1. Hochberg MC, Altman RD, Brandt KD, et al. Guidelines for the medical management of osteoarthritis. Part II. Osteoarthritis of the knee. Arthritis Rheum. 1995;38:15411546.

2. Calkins E. Management of rheumatoid arthritis and the other autoimmune rheumatic diseases. In: Hazzard WR, Blass JP, Ettinger J, W.H., Halter JB, Ouslander JG, eds. Principles of Geriatric Medicine and Gerontology. 4th ed. New York: McGraw-Hill; 1999:1135-1153.

3. American College of Rheumatology Subcommittee on Rheumatoid Arthritis Guidelines. Guidelines for the management of rheumatoid arthritis: 2002 Update. Arthritis Rheum. 2002;46:328-346.

4. Creamer P, Hochberg MC. Management of osteoarthritis. In: Hazzard WR, Blass JP, Ettinger WH, Halter JB, Ouslander JG, eds. Principles of Geriatric Medicine and Gerontology. 4th ed. New York: McGraw-Hill; 1999:1155-1162. 
5. American Geriatrics Society Panel on Exercise and Osteoarthritis. Exercise prescription for older adults with osteoarthritis pain: consensus practice recommendations. A supplement to the AGS Clinical Practice Guidelines on the management of chronic pain in older adults. J Am Geriatr Soc. 2001;49:808-823.

6. Hurley MV, Mitchell HL, Walsh N. In osteoarthritis, the psychosocial benefits of exercise are as important as physiological improvements. Exerc Sport Sci Rev. 2003;31: 138-143.

7. Penninx BW, Rejeski WJ, Pandya J, et al. Exercise and depressive symptoms: a comparison of aerobic and resistance exercise effects on emotional and physical function in older persons with high and low depressive symptomatology. J Gerontol B Psychol Sci Soc Sci. 2002;57:P124-P132.

8. Arthritis Foundation Association of State and Territorial Health Officials and Centers for Disease Control and Prevention. National Arthritis Action Plan: A Public Health Strategy. Atlanta, GA: Centers for Disease Control and Prevention; 1999.

9. US Dept of Health and Human Services. Healthy People 2010: Understanding and Improving Health, 2nd ed. Washington: US Govt Printing Office; November 2000.

10. Pate RR, Pratt M, Blair SN, et al. Physical activity and public health. A recommendation from the Centers for Disease Control and Prevention and the American College of Sports Medicine. JAMA. 1995;273:402-407.

11. Hootman JM, Macera CA, Ham SA, Helmick CG, Sniezek JE. Physical activity levels among the general US adult population and in adults with and without arthritis. Arthritis Rheum. 2003;49:129-135.

12. Stenstrom $\mathrm{CH}$, Minor MA. Evidence for the benefit of aerobic and strengthening exercise in rheumatoid arthritis. Arthritis Rheum. 2003;49:428-434.

13. Castañeda DM, Bigatti S, Cronan TA. Gender and exercise behavior among women and men with osteoarthritis. Women Health. 1998;27:33-53.

14. Zimmer Z, Hickey T, Searle MS. Activity participation and well-being among older people with arthritis. The Gerontologist. 1995;35:463-471.

15. Oliver K, Cronan T. Predictors of exercise behaviors among fibromyalgia patients. Prev Med. 2002;35:383-389.

16. Kaplan MS, Huguet N, Newsom JT, McFarland BH. Characteristics of physically inactive older adults with arthritis: results of a population-based study. Prev Med. 2003;37:61-67.

17. Fontaine KR, Heo M, Bathon J. Are US adults with arthritis meeting public health recommendations for physical activity? Arthritis Rheum. 2004;50:624-628.

18. Dexter PA. Joint exercises in elderly persons with symptomatic osteoarthritis of the hip or knee. Performance patterns, medical support patterns, and the relationship between exercising and medical care. Arthritis Care Res. 1992;5:36-41.

19. Carpenter JO, Davis LJ. Medical recommendations-followed or ignored? Factors influencing compliance in arthritis. Arch Phys Med Rehabil. 1976;57:241-246.

20. Munneke M, de Jong Z, Zwinderman AH, et al. Adherence and satisfaction of rheumatoid arthritis patients with a long-term intensive dynamic exercise program (RAPIT program). Arthritis Rheum. 2003;49:665-672.

21. Rejeski WJ, Brawley LR, Ettinger W, Morgan T, Thompson C. Compliance to exercise therapy in older participants with knee osteoarthritis: implications for treating disability. Med Sci Sports Exerc. 1997;29:977-985.

22. Gecht MR, Connell KJ, Sinacore JM, Prohaska TR. A survey of exercise beliefs and exercise habits among people with arthritis. Arthritis Care Res. 1996;9:82-88. 
23. Da Costa D, Dobkin PL, Dritsa M, Fitzcharles MA. The relationship between exercise participation and depressed mood in women with fibromyalgia. Psychol, Health Med. 2001;6:301-311.

24. Seçkin U, Gündüz S, Borman P, Akyüz M. Evaluation of the compliance to exercise therapy in patients with knee osteoarthritis. J Back Musculoskeletal Rehabil. 2000;14: 133-137.

25. Neuberger GB, Kasal S, Smith KV, Hassanein R, DeViney S. Determinants of exercise and aerobic fitness in outpatients with arthritis. Nurs Res. 1994;43:11-17.

26. O'Carroll M, Hendriks O. Factors associated with rheumatoid arthritis patients' compliance with home exercise and splint use. Physiotherapy Pract. 1989;5:115-122.

27. Stenström CH, Arge B, Sundbom A. Home exercise and compliance in inflammatory rheumatic diseases - a prospective clinical trial. J Rheumatol. 1997;24:470-476.

28. Kamwendo K, Askenbom M, Wahlgren C. Physical activity in the life of the patient with rheumatoid arthritis. Physiotherapy Res Int. 1999;4:278-292.

29. Gyurcsik NC, Estabrooks PA, Frahm-Templar MJ. Exercise-related goals and selfefficacy as correlates of aquatic exercise in individuals with arthritis. Arthritis Rheum. 2003;49:306-313.

30. Buckelew SP, Murray SE, Hewett JE, Johnson J, Huyser B. Self-efficacy, pain, and physical activity among fibromyalgia subjects. Arthritis Care Res. 1995;8:43-50.

31. Buckelew SP, Huyser B, Hewett JE, et al. Self-efficacy predicting outcome among fibromyalgia subjects. Arthritis Care Res. 1996;9:97-104.

32. Culos-Reed SN, Brawley LR. Fibromyalgia, physical activity, and daily functioning: the importance of efficacy and health-related quality of life. Arthritis Care Res. 2000;13:343-351.

33. Barlow JH. Understanding exercise in the context of chronic disease: an exploratory investigation of self-efficacy. Percept Mot Skills. 1998;87:439-446.

34. Iversen MD, Fossel AH, Daltroy LH. Rheumatologist-patient communication about exercise and physical therapy in the management of rheumatoid arthritis. Arthritis Care Res. 1999;12:180-192.

35. Ferguson K, Bole GG. Family support, health beliefs, and therapeutic compliance in patients with rheumatoid arthritis. Patient Couns Health Educ. 1979;1:101-105.

36. Terpstra SJ, de Witte LP, Diederiks JPM. Compliance of patients with an exercise program for rheumatoid arthritis. Physiotherapy Canada. 1992;44:37-41.

37. Hammond A. The use of self-management strategies by people with rheumatoid arthritis. Clin Rehabil. 1998;12:81-87.

38. Lambert BL, Butin DN, Moran D, et al. Arthritis care: comparison of physicians' and patients' views. Semin Arthritis Rheum. 2000;30:100-110.

39. Jensen GM, Lorish CD. Promoting patient cooperation with exercise programs: linking research, theory, and practice. Arthritis Care Res. 1994;7:181-189.

40. Belza B, Topolski T, Kinne S, Patrick DL, Ramsey SD. Does adherence make a difference? Results from a community-based aquatic exercise program. Nursing Research. 2002;51:285-291.

41. Sundstrom B, Ekergård H, Sundelin G. Exercise habits among patients with ankylosing spondylitis. A questionnaire based survey in the County of Vasterbotten, Sweden. Scand J Rheumatol. 2002;31:163-167.

42. Schachter CL, Busch AJ, Peloso PM, Sheppard MS. Effects of short versus long bouts of aerobic exercise in sedentary women with fibromyalgia: a randomized controlled trial. Phys Ther. 2003;83:340-358. 
43. Sullivan T, Allegrante JP, Peterson MG, Kovar PA, MacKenzie CR. One-year followup of patients with osteoarthritis of the knee who participated in a program of supervised fitness walking and supportive patient education. Arthritis Care Res. 1998;11:228233.

44. Minor MA, Brown JD. Exercise maintenance of persons with arthritis after participation in a class experience. Health Educ Q. 1993;20:83-95.

45. Kurtze N, Gundersen KT, Svebak S. Quality of life, functional disability and lifestyle among subgroups of fibromyalgia patients: the significance of anxiety and depression. Br J Med Psychol. 1999;72 ( Pt 4):471-484.

46. Eurenius E, Biguet G, Stenström CH. Attitudes toward physical activity among people with rheumatoid arthritis. Physiotherapy Theory Pract. 2003;19:53-62.

47. Goldman JA. Hypermobility and deconditioning: important links to fibromyalgia/ fibrositis. South Med J. 1991;84:1192-1196.

48. Trost SG, Owen N, Bauman AE, Sallis JF, Brown W. Correlates of adults' participation in physical activity: review and update. Med Sci Sports Exerc. 2002;34:1996-2001.

49. Rejeski WJ, Ettinger WH, Jr., Martin K, Morgan T. Treating disability in knee osteoarthritis with exercise therapy: a central role for self-efficacy and pain. Arthritis Care Res. 1998;11:94-101.

50. Ettinger WH, Jr., Burns R, Messier SP, et al. A randomized trial comparing aerobic exercise and resistance exercise with a health education program in older adults with knee osteoarthritis. The Fitness Arthritis and Seniors Trial (FAST). JAMA. 1997;277: 25-31.

51. Bauman AE, Sallis JF, Dzewaltowski DA, Owen N. Toward a better understanding of the influences on physical activity. The role of determinants, correlates, causal variables, mediators, moderators, and confounders. Am J Prev Med. 2002;23(2 Suppl 1):5-14.

52. Rothman AJ. Toward a theory-based analysis of behavioral maintenance. Health Psychol. 2000;19(1 Suppl):64-69.

53. Sallis JF, Owen N. Determinants of physical activity. Physical Activity and Behavioral Medicine. Thousand Oaks, CA: Sage Publications; 1999:110-134. 